\title{
Experiment Study on Improved Closed Loop Pulsating Heat Pipe with Silver/Water Nanofluid
}

\author{
Weixiu Shi ${ }^{1, a}$, Weiyi $\mathrm{Li}^{2, \mathrm{~b}}$ and Lisheng Pan ${ }^{3, \mathrm{c}}$ \\ ${ }^{1}$ School of Environment and Energy Engineering, Beijing University of Civil Engineering and \\ Architecture, Beijing 100044, China \\ 2 Department of Thermal Engineering, Tianjin University, Tianjin 300072, China \\ ${ }^{3}$ State Key Laboratory of High-temperature Gas Dynamics, Institute of Mechanics, Chinese \\ Academy of Sciences, Beijing 100190, China \\ ashiweixiu@bucea.edu.cn, byli@tju.edu.cn, ${ }^{\mathrm{c}}$ panlisheng@imech.ac.cn
}

Keywords: nanofluid, improved closed loop, pulsating heat pipe, start up, operation stability, heat transfer

\begin{abstract}
Start up and heat transfer performances of improved closed loop pulsating heat pipe (ICLPHP) charged with water and silver/water nanofluid, respectively, were investigated experimentally with angles of $90^{\circ}$ and $60^{\circ}$. Both the average evaporator wall temperature and the overall thermal resistance of the ICLPHP with different working fluids and at the volume filling ratio of $35 \%$ were tested and compared. Experimental results showed that nanofluid caused different thermal performances of ICLPHP. Within the experiment range, silver/water nanofluid can improve operation stability and heat transfer limit and reduce starting power compared with water. With high heating power, thermal resistance of nanofluid was lower than that of water. With inclination of $60^{\circ}$, ICLPHP with nanofluid operated better and reduced sensitivity of inclination.
\end{abstract}

\section{Introduction}

Pulsating heat pipes (PHPs) were first proposed by Akachi[1] in the 90's. PHPs were bended by capillary copper tubes, and the working fluids distributed in PHPs with vapor plug and liquid slug. Heat transfer can achieve by the motion of vapor plug and liquid slug between heating section and cooling section. With the great demand for dissipating increasing higher heat fluxes from devices including, but not limited to, electronics, many efforts have been devoted to develop heat transfer enhancement technologies. According to three types (closed loop, closed loop with check valve, open loop), which are showed in Fig.1, the ICLPHP was proposed in this paper, and the structure was displayed in Fig.2.

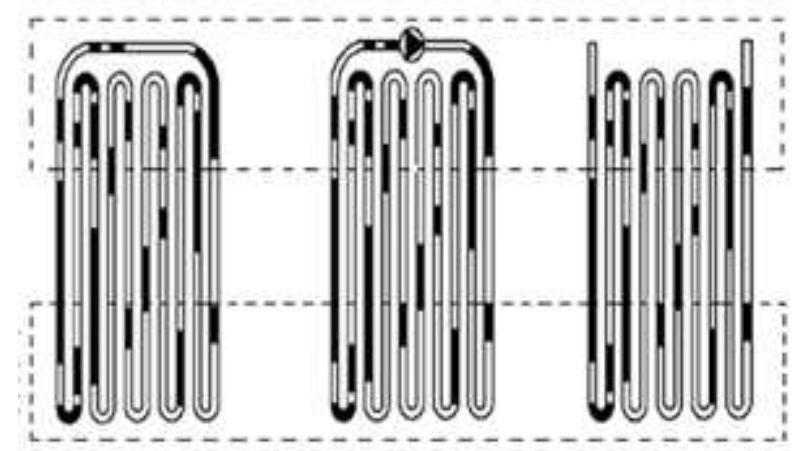

Fig.1 Three types of PHPs

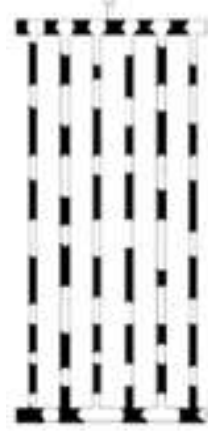

Fig.2 Structure of ICLPHP

At present, multi-bends closed loop pulsating heat pipe charged with nanofluid is studied by many researchers, especially in experiments. Lin et al.[2] introduced water-based silver particle nanofluids into a multi-bends PHP. They examined the effect of structural characteristics of nanoparticles on PHP thermal performance and found that the average temperature difference and the thermal resistance of evaporator and condenser are decreased by $7.79^{\circ} \mathrm{C}$ and $0.092^{\circ} \mathrm{C} / \mathrm{W}$, respectively. 
A similar experiment was performed by shang et al.[3] It was found that $\mathrm{Cu} /$ water nanofluids in self-exciting mode oscillating-flow (SEMOS) heat pipes have their own heat transfer particularities. Though, under certain conditions, nanofluids themselves can enhance heat transfer, but the filling rate should be the parameter that determines the heat transfer performance. Li et al.[4][5] conducted an experimental investigation to study the flow pattern and heat transfer effects by infrared photography instrument. The results demonstrated that PHP with $\mathrm{SiO} 2 /$ water nanofluid can decrease heat transfer lower limit and improve heat transfer upper limit. Qu et al.[6] investigated thermal performances of two same oscillating heat pipes charged with $\mathrm{SiO} 2 /$ water and $\mathrm{Al} 2 \mathrm{O} 3 /$ water nanofluids experimentally, respectively. Their results showed that thermal resistances can decrease by $23.7 \%$ and $25.7 \%$, respectively. Ma et al.[7] found that the heat transport capability of oscillating heat pipe could reach a thermal resistance of $0.3{ }^{\circ} \mathrm{C} / \mathrm{W}$ at a heat input of 336W. The results by Wannapakhe et al.[8] indicated that silver nanofluid could increase the heat flux by more than $10 \%$ compared with pure water.

As investigations above, although most pulsating heat pipes charged with nanofluids had higher thermal properties under the given condition, there are still discrepancies. To give an insight into the heat transfer improvement mechanism caused by nanofluid, an experimental investigation with ICLPHP has been performed. Compared with water, both positive and negative effects on the thermal performance are found for the ICLPHP charged with silver/water nanofluid.

\section{Experimental Apparatus and Procedure}

The schematic diagram of experimental apparatus is shown in Fig.3. The experimental apparatus consists of heating and cooling system, high speed dynamic data collecting system, ICLPHP and other accessories. The ICLPHP is made of copper tube including ten vertical tubes and two horizontal tubes. Vertical tubes are with inside diameter of $2 \mathrm{~mm}$ and outside diameter of $3 \mathrm{~mm}$, and horizontal tubes are with inside diameter of $3 \mathrm{~mm}$ and outside diameter of $6 \mathrm{~mm}$. The ICLPHP is of $365 \mathrm{~mm}$ height and $135 \mathrm{~mm}$ width. The height of condensation section is $105 \mathrm{~mm}$, and one horizontal tube in the bottom is used as heating section.

The heating system includes heating wire, transformer, ammeter and voltmeter. Different heating powers are achieved by adjusting the transformer. Outer surface of heating section is winded by Nichrome wire uniformly to simulate uniform heating. Current and voltage can be directly showed by ammeter and voltmeter, respectively. Cooling water bath with one end connecting to the faucet is used to condensate the working fluid. Outer surfaces, including heating section and insulation section, are insulated by double-layer polyurethane with thickness of every layer of $25 \mathrm{~mm}$ to reduce heat loss. Temperature variations are automatically monitored by a data acquisition unit (HP-34970A). The unit can not only show and check the real time data but also save the pulsating curves. Copper-constantan thermal couples with high accuracy are used in the system ( $\mathrm{T}$ is the measuring point). The absolute pressure value of heat pipe can reach $4 \times 103 \mathrm{~Pa}$.

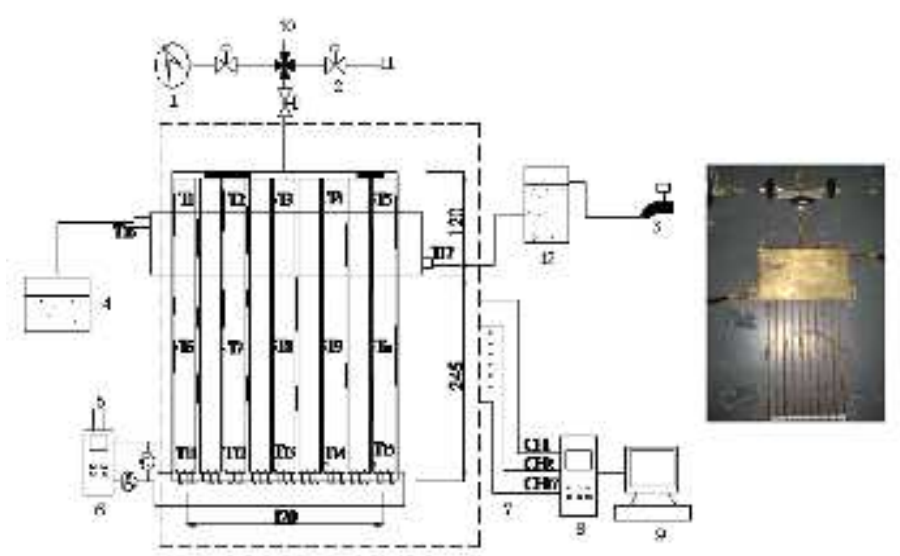

1 vacuum gauge, 2 control valve, 3 faucet, 4 pool, $5 \mathrm{AC}$ voltage 220V, 6 transformer, 7 thermal-couple, 8 data collector, 9 computer, 10 filling fluid port, 11 vacuum port, 12 constant pressure tank

Fig.3 The schematic diagram of experimental apparatus 
Experimental apparatus is fixed on the rotary platform to change inclination of PHP. Inclinations are between rotary platform and horizontal plane.

At volume filling ratio of 35\%, heat transfer performances brought by nanofluid are analyzed with distilled water and $0.05 \mathrm{wt} \%$ silver/water nanofluid and inclinations of $90^{\circ}$ and $60^{\circ}$.

\section{Experimental Results and Discussions}

The starting evaporator wall temperature charged with water on the conditions of $63 \mathrm{~W}$ and $115 \mathrm{~W}$ are shown in Fig.4 and Fig.5, respectively. The starting evaporator wall temperature charged with silver/water on the condition of $61 \mathrm{~W}$ is shown in Fig.6.

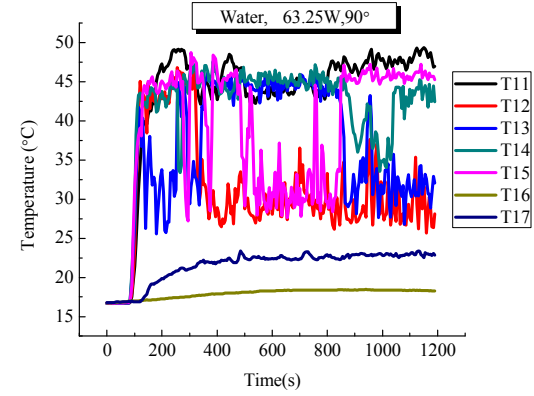

Fig.4 At $63.25 \mathrm{~W}$

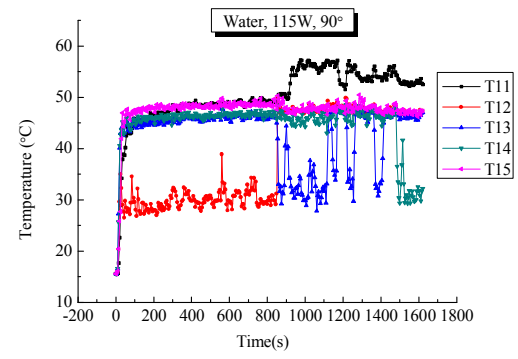

Fig.5 At $115 \mathrm{~W}$

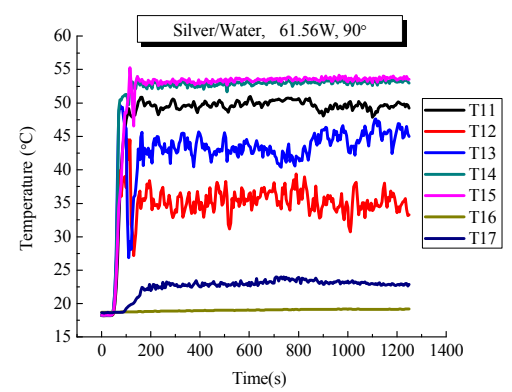

Fig.6 At $61.56 \mathrm{~W}$

It is clearly from Fig. 4 that evaporator wall temperature charged with water on the condition of $63 \mathrm{~W}$ changes greatly, variation range of which is with the range of $20^{\circ} \mathrm{C}$. Therefore, the pulsating heat pipe can't start stably at $63 \mathrm{~W}$. Operation stability is stronger with the power rising up to $115 \mathrm{~W}$. Moreover, the ICLPHP takes on high frequency and small amplitude from 0 s to $800 \mathrm{~s}$, and then it oscillates greatly from 800 s to 1600 s. At the same time, the flow direction of working fluid changes according to temperature variation. As shown in Fig.5, ICLPHP charged with silver/water at $61 \mathrm{~W}$ can start up stably, and evaporator wall temperature oscillates small with the maximum amplitude of $5^{\circ} \mathrm{C}$.

Nanofluid is suggested to influence the heat transfer due to the following reasons. First, thermal conductivity of based fluid can be enhanced by adding nano-particles, which is beneficial to heat transfer rapidly. Second, physical properties of based fluid are changed by nano-particles, which result in existing state of nanofluid different from that of water before starting. Finally, there are lots of bubbles in liquid slug of nano-fluid, and the bubbles can not only enhance contact area (heat transfer area) between liquid and inner wall of ICLPHP but also increase number of nucleation sites. Expansion of bubbles can provide the power for working fluid movement and make starting of PHP easier. In a word, within the experiment range, silver/water nanofluid can improve operation stability and reduce starting power compared with water.

Evaporator wall temperature charged with water and silver/water at high power are shown in Fig.7 and Fig.8, respectively. Fig 7 shows operation of ICLPHP is stable with inclination of $60^{\circ}$. Because working fluid possesses drastic phase transition, strong pressure fluctuation can bring out better evaporator and condensation of working fluid with power of $387 \mathrm{~W}$ and $423 \mathrm{~W}$, and the amplitude and cycle are small. The phase transition becomes stronger with power increasing to $489 \mathrm{~W}$. At the same time, working fluid oscillates drastically, leading to bigger amplitude and cycle. The operation of PHP begins from stable stage transmitting to dry-burning stage. Fig. 8 indicates that evaporator temperature oscillates stably with power from $335 \mathrm{~W}$ to $478 \mathrm{~W}$. With power increasing to $567 \mathrm{~W}$, the temperature increases from about $80^{\circ} \mathrm{C}$ up to about $90^{\circ} \mathrm{C}$. When power continue to increase to $641 \mathrm{~W}$, the temperature rises immediately up to $115^{\circ} \mathrm{C}$, resulting in local overheat. The temperature reaches $120^{\circ} \mathrm{C}$ with power of $695 \mathrm{~W}$. However, wall temperature oscillates stably in high temperature. 

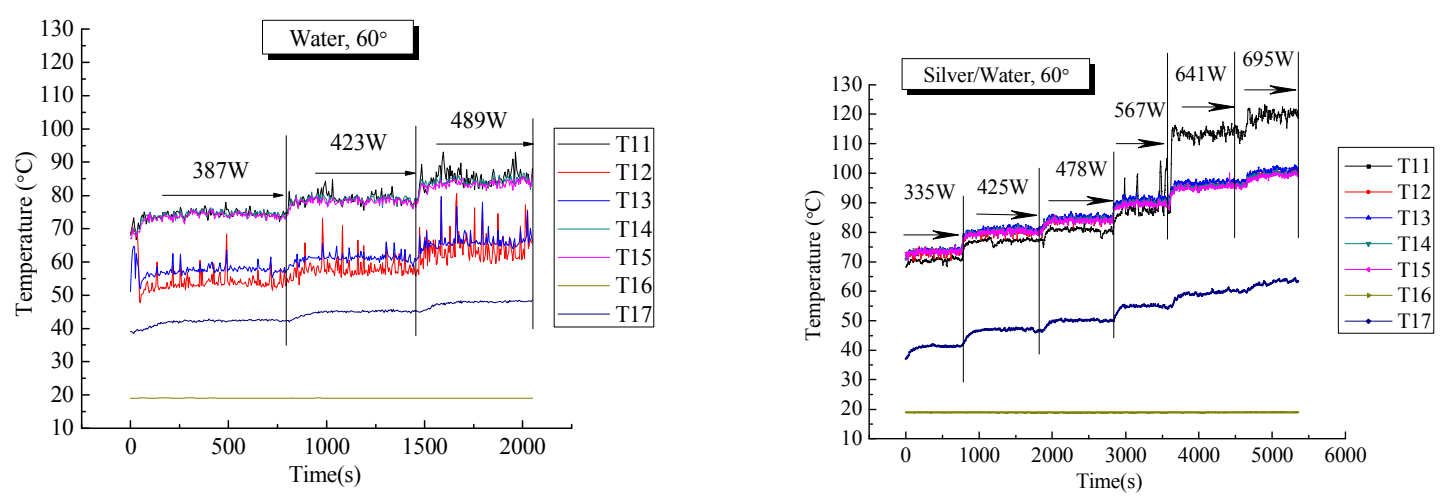

Fig.7 Evaporator temperature variation of water Fig.8 Evaporator temperature variation of silver/water

Thermal resistance of ICLPHP charged with different working fluids with inclinations of $90^{\circ}$ and $60^{\circ}$ are showed in Fig.9 and Fig.10, respectively.

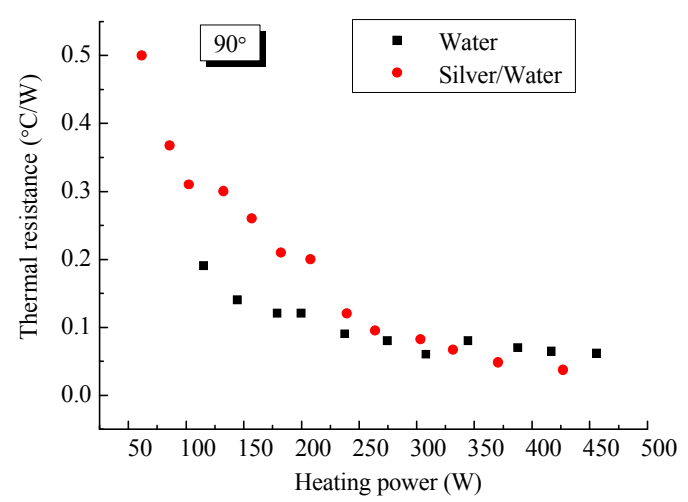

Fig.9 Thermal resistance variation of $90^{\circ}$

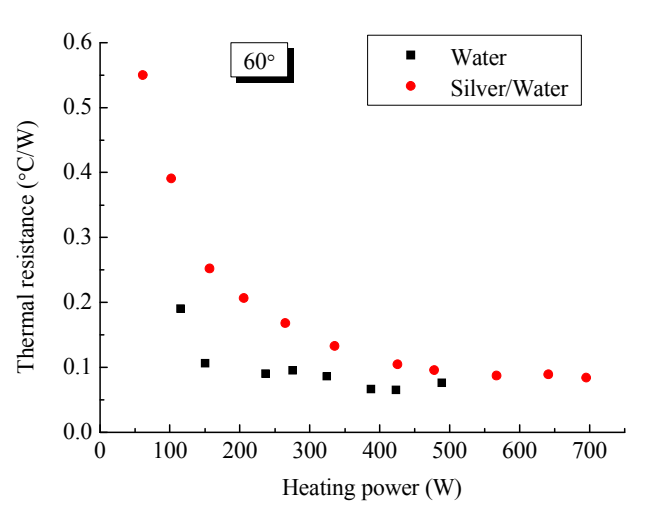

Fig.10 Thermal resistance variation of $60^{\circ}$

As shown in Fig.9, thermal resistance decreases with heating power increasing. The working fluid pulsates intensively and transfers heat from evaporator section to condensation section frequently. With heating power lower than $325 \mathrm{~W}$, thermal resistance charged with water is lower than that with silver/water. However, with heating power higher than $325 \mathrm{~W}$, thermal resistance charged with silver/water is lower than that with water, which indicates that ICLPHP charged with silver/water is more suitable for higher heating power compared with water. As shown in Fig.10, with inclination of $60^{\circ}$, thermal resistance charged with water is lower than that with nanofluid within experimental range. However, thermal resistance with water presents rising trend from $500 \mathrm{~W}$, which reveal that operation state transmits to dry burning state from steady state and heat transfer effects get worse. However, thermal resistance with silver/water presents a downward trend with increasing power. For all that, thermal resistance changes very little and tends to be stable from $500 \mathrm{~W}$ to $700 \mathrm{~W}$, which reveal that heat transfer limit is about $700 \mathrm{~W}$. PHP with nanofluid can improve heat transfer limit.

Viscosity of based fluid and flow resistance of working fluid can increase because of adding nano-paticle. Therefore, heat transfer effect with water is better than that with nanofluid at low heating power. However, the higher is heating power, the larger are driving force of working fluid and disturbance degree of nano-particle. Surface roughness of inner wall can be changed by attaching nano-particle, leading to increasing of convective surface heat transfer coefficient. At the same time, the nano-particle suspended in ICLPHP moves drastically because of pressure imbalance, resulting in collision among particle, based fluid and inner wall. According to the above reasons, heat transfer performances improve obviously and thermal resistance decreases evidently. 


\section{Conclusions}

An experimental study has been carried out to compare and analyze the different heat transfer performances of ICLPHP, which were charged with silver/water nanofluid and water, respectively. The following conclusions are obtained from the present work:

(1) Starting power can be decreased by charging with silver/water nanofluid. ICLPHP charged with silver/water at $61 \mathrm{~W}$ can start up stably. However, evaporator wall temperature charged with water on the condition of $63 \mathrm{~W}$ changes greatly, variation range of which is with the range of $20^{\circ} \mathrm{C}$.

(2) ICLPHP charged with silver/water is more suitable for higher heating power compared with water. With heating power lower than $325 \mathrm{~W}$, thermal resistance charged with water is lower than that with silver/water. However, with heating power higher than $325 \mathrm{~W}$, thermal resistance charged with silver/water is lower than that with water.

(3) Within the experiment range, silver/water nanofluid can improve operation stability and heat transfer limit compared with water. With the angle of $60^{\circ}$, ICLPHP with nanofluid operates stably and decrease the sensitivity for angle compared with water.

\section{Acknowledgements}

This work was financially supported by Funding Project for Academic Human Resources Development in Institutions of Higher Learning Under the Jurisdiction of Beijing Municipality (No.PHR201007127).

\section{References}

[1] H Akachi, F Polasek, P Stulc. Pulsating heat pipes[C]// Proceedings of the Fifth International Heat Pipe Symposium, Melbourne, Austria (1996)

[2] Y.H. Lin, C.C. Hsu, H.L. Chen, et al. Experimental Investigation of Silver Nano-fluid on Pulsating Heat PiPe Thermal Performance[C]// Proeeedings of the 8th International Heat Pipe Symposium, Kumamoto, Japan(2006)

[3] Fumin Shang, Dengying Liu, Haizhen Xian, et al: Journal of Power Engineering, Vol. 27(2007), p.233-236

[4] Qiming Li, Xiaofeng Peng, Buxuan Wang: Journal of engineering thermalphysics, Vol. 29 (2008), p. 479-481

[5] Qiming Li, Zou Jiang, Yang Zhen, et al : J. Heat Trans, Vol. 133(2011), p.052901(1-5)

[6] Jian Qu, Huiying Wu: International Journal of Thermal Sciences, Vol. 50(2011), p. 1954-1962

[7] H.B. Ma, C. Wilson, Q. Yu, et al: J. Heat Trans. Vol. 128(2006), p. 1213-1216

[8] S. Wannapakhe, S. Rittidech, B. Bubphachot, et al: Journal of Mechanical Science and Technology, Vol. 23(2009), p. 1576-1582 